\title{
Collaborative practice in action: Building interprofessional competencies through simulation based education and novel approaches to team training
}

\author{
Alyshah Kaba ${ }^{1}$, Mirette Dubé2 ${ }^{2}$ Irina Charania ${ }^{3}$ and Marlene Donahue ${ }^{4}$ \\ ${ }^{1}$ Provincial Lead Research Scientist, eSim Provincial Program, Alberta Health Services, Department of Community Health Sciences, Cumming School of Medicine, \\ University of Calgary, Canada \\ ${ }^{2}$ Project Manager, Simulation Consultant eSIM provincial program, Alberta Health Services, KidSim Research Coordinator (Sim for Life), Cumming School of \\ Medicine, University of Calgary, Canada \\ ${ }^{3}$ Simulation Consultant, eSIM provincial program, Alberta Health Services, Advanced Technical Skills Simulation Laboratory (ATSSL), Cumming School of \\ Medicine, University of Calgary, Canada \\ ${ }^{4}$ Director eSIM Provincial Program, Alberta Health Services, Research Coordinator, Faculty of Nursing, University of Calgary, Canada
}

\begin{abstract}
Background: Interprofessional collaboration (IPC) is integral to patient safety and quality of care. The demand for research evidence for IPC competency based education continues to grow globally for practicing healthcare professionals.

Purpose: To design, deliver and evaluate an IPC competency based simulation curriculum for frontline interprofessional healthcare teams using the CIHC (Canadian Interprofessional Health Collaborative) competency framework.

Methods: Intervention included a flip classroom approach of 4.5 hours of asynchronous eLearning on IPC, and two 4.5 hour facilitated workshops inclusive of four contextual simulations and 2 team based experiential learning activities, each followed by targeted debriefing on the IPC competencies.

Discussion: This novel approach of using simulation based education (SBE) and debriefing coupled with team based experiential activities resulted in a statistically significantly changed in individual cognitive awareness, interprofessional attitudes and team behaviors $(p<0.05)$.

Conclusion: There are very few reported opportunities for frontline healthcare teams to practice and gain proficiency in knowledge, skills and attitudes related to IPC. To demonstrate behavioral change in IPC competencies, frontline practitioners require a combined approach of foundational learning, non-medical experiential team based activities and simulation based learning.
\end{abstract}

\section{Introduction}

Healthcare practitioners work in dynamic, high-pressure clinical environments that require individuals to work collaboratively as part of health care teams and respond to the increasing demands of patient care needs [1]. Interprofessional Collaboration (IPC) and teamwork training is vital to patient safety and quality of care in healthcare [26]; although effective IPC is not always modeled or understood in the clinical settings by experienced health professionals. Over the last 15 years there has been increased recognition and momentum in wanting to achieve IPC [7-9]. This awareness of moving towards high quality and collaborative care delivery has resulted in a shift of understanding that health professionals need to be competent in their individual roles, but we also require these same individuals to think and act as a collectively competent team members [10].

While we have made some progress for the need for IPC globally, healthcare providers still struggle with a number of emerging challenges which include a) how to design, deliver and debrief experiential based Interprofessional Education (IPE) curriculum to effectively teach team effectiveness and collaborative practice b) how to apply collaborative practice competencies given the unique variances between different contexts and clinical settings and c) how to measure changes in knowledge, attitudes and individual team behaviors following these types of educational interventions [11]. Tackling these identified barriers is critical to responding to the increasing pressures to design curriculum, implement, and measure collaborative practice for the meaningful changes in IPC [12-14]. Furthermore, there is a major shift required on a global scale for educators who have traditionally designed, delivered and debriefed health professional education in health profession silos [15]. New evidence based approaches to deliver and design IPE/IPC curriculum with the goal of building collective competence in healthcare teams suggests new ways to think and design

${ }^{\star}$ Correspondence to: Alyshah Kaba, Provincial Lead Research Scientist, eSim Provincial Program, Alberta Health Services, Department of Community Health Sciences, Cumming School of Medicine, University of Calgary, Canada, E-mail: alyshah.kaba@albertahealthservices.ca

Key words: Interprofessional Collaboration (IPC); Interprofessional Education (IPE); Simulation Based Education (SBE); Collective Competence; Collaborative Practice; Health Professions; Team effectiveness, Team Training, Simulation

Received: July 19, 2018; Accepted: July 23, 2018; Published: July 27, 2018 
innovative solutions [16]. We cannot expect to see meaningful positive changes in IPC outcomes if we do not examine critically the application of these new evidence based approaches to IPC education.

\section{The current state of IPE/IPC education}

In line with historical norms, healthcare providers continue to be largely trained in professional silos [15]. Rather than an individual practitioner perspective, interprofessional collaboration is the "process of developing and maintaining effective interprofessional working relationships with learners, practitioner, patient/clients/families" [9]. In 2010, the CIHC (Canadian Interprofessional Health Collaborative), working group was mandated to review the literature related to Interprofessional (IP) competencies, IPE and IPC competency frameworks and develop a Canada-wide IPC framework to promote standardized language and taxonomy of IPC. The framework provides descriptions of knowledge, skills, attitudes and values of the six competencies required for effective interprofessional collaboration practice which include: 1) interprofessional communication, 2) patient/client/family /community-centered care, 3) role clarification, 4) team functioning, 5) collaborative leadership, and 6) interprofessional conflict resolution [9]. In response to the development of the CIHC competency framework, there were a growing number of requirements by accreditation bodies for IPE curriculum to be embedded in Canadian health professional programs [17]. In addition, there have been a myriad of educational resources developed over the last 15 years targeting IPC and IPE (e.g. team training workshops, webinars, online modules, student led clubs, orientation days, standardize patient group histories, case studies, virtual patients etc.) [18]. However, many of these educational activities have focused primarily on healthcare professional students and not practicing health professionals and frontline clinical teams $[8,19]$.

The current state of education and initiatives for addressing gaps in IPC and general teamwork training among practicing healthcare professionals have either a) focused on changing team behaviors through the implementation of new tools and processes without explicit training directed at addressing the contextual clinical environment of a team (e.g. TeamSTEPPS) $[11,20]$ instead of focusing on generalized teamwork behaviors using undifferentiated non-medical experiential activities/and change management tools or b) has occurred through the use of simulation based educated (SBE) where team behaviours are addressed in the contextual and hierarchical elements within which the behaviours and challenges in team dynamics occurred [21].

There are many advantages and challenges of both educational approaches of non-medical team based experiential activities and SBE. For example, there is increasing evidence surrounding curricular design relative to teamwork training that addressed the use of experiential team based activities for healthcare teams that remove the medical context and hierarchical roles [22-24]. Programs such as TeamSTEPPS have been successful in using undifferentiated nonmedical experiential activities for team training and are being widely adopted in healthcare organizations in promoting evidence-based set of teamwork tools, aimed at optimizing patient outcomes by improving communication and teamwork skills among health care professionals. However, the challenge with these types of programs is they often use "experts" and standardized and scripted approaches in the development of training that is not contextual to the local environments [20,25]. Unless championed by clinical teams, these programs, which remove the focus on medical skills and expertise, often lack buy-in and report poor sustained behavioural change in IPC [20].
Similarly, myriad of research evidence recommends that SBE be utilized for team training $[6,26,27]$. Over the last 15 years SBE is increasingly used to provide opportunities for healthcare practitioners to collaborative learn and engage in reflective practice [14,28]. Debriefing and guided reflection following the simulation is a critical component of the learning, where learners can discuss areas for improvement as a team, which can result in potential change in behaviors [29]. To be relevant, teaching teamwork training in healthcare by deliberate practice using simulation and debriefing is grounded in clinically contextualized scenarios $[11,30,31]$ that take into consideration the unique variances between different contents and clinical environments. However, a potential shortfall of an IPC curriculum that only used SBE to teach teamwork training, is that learners may become fixated on the medical content, which does not readily allow for the deconstruction of underlying beliefs and assumptions, regarding why a team had developed certain norms and how they are either promote or discourage IPC [24,32]. While there is evidence and research supporting both educational approaches $[12,15,33]$ there is paucity of evidence that uses a combination of educational strategies of both nonmedical experiential team based activities and SBE to teach IPC. There are few opportunities for practicing healthcare professionals to practice and gain proficiency in knowledge, skills and attitudes related to IPC that include a combination of foundational knowledge, non-medical team based experiential activities and simulation based learning.

The aim of this paper is to describe the results of the competency based interprofessional simulation based curriculum that was developed for practicing frontline healthcare teams. The study used a combination of foundational learning, experiential team based activities and SBE for healthcare teams, aimed in building competence in IPC and using the CIHC competency framework. Funded by the government of Alberta, the Health Workforce Action Plan (HWAP) included a 1.15-milliondollar provincial grant to address this identified need. The purpose of this 3-year funded initiative was to design deliver a competency based experiential interprofessional simulation intervention for healthcare professionals and measure change in knowledge, attitudes and individual team behaviors.

\section{Description of curricular intervention}

The curriculum design followed the Kern six-step approach [34], integrating evidenced based approaches for IPC and teamwork training in healthcare along with expert consultation from senior leaders in the health authority, government and health professional programs. The intervention was developed to address the results of both the general and targeted needs assessments to diagnose the greatest IPC challenges unique for each specific healthcare team. This targeted needs assessment data was then used to design the specific IP scenarios, objectives and debriefing for each of the frontline teams. The curriculum was broken up into three distinct components that were completed sequentially by each participant. All foundational knowledge on IPC content was delivered via 4.5 hours of asynchronous eLearning modules as part of the first component, in accordance with flipped classroom principles $[35,36]$. This flip classroom approach enabled a common knowledge at baseline to be established for all participants on IPC competencies. The second and third components were two 4.5 hours facilitated inperson workshops that were designed to allow participants to apply interprofessional collaborative practice principles as they completed a series of two simulation scenarios and one non-medical experiential team based activities. Deliberate reflection on interprofessional collaborative practice competencies was fostered through the debriefing sessions that followed each simulation and non-medical experiential 
team based activity. The debriefing sessions was co-led by trained simulation consultants and project team members from at least two, and often three difference healthcare professions (e.g. physician, nurse and respiratory therapist) and were allotted two times the duration of the simulation or activity in which they followed. Debriefing sessions were conducted according to PEARLS (Promoting Excellence and Reflective Learning in Simulation) which utilizes a mixed method approach to debriefing that is focused on the learners needs and learning context [37]. The primary focus of the debriefing was on the pre determined objectives developed using the CIHC competencies for each simulation or non-medical team based experiential activity. The focused reflection on collaborative practice competencies and underlying personal assumptions and beliefs was intended to foster transformative learning and behavioral change for the participants.

The asynchronous eLearning modules were considered foundational for the entire program and were completed by everyone involved with the project, whether as a participant or unit specific clinical champion project team member. The structure for the two 4.5 facilitated workshops were standardized for all three units that participated in this project, as were the non-medical team based experiential activities. The simulation scenarios were co-created and developed for each unit's specific context based on the targeted needs assessment results. A core clinical champion project team was brought together for each participating unit. This clinical champion project team included representatives from each profession in their interprofessional team and medically relevant simulations were codeveloped alongside the faculty team. After completing the eLearning module this clinical champion project team participated in a threeday training workshop, led by the faculty team which further explored simulation and debriefing as teaching modalities, as well as how the $\mathrm{CIHC}$ competencies were applicable to their specific team environment and clinical context. The initial development stages for the simulation scenarios were completed during these workshops, including the identification of relevant medical objectives paired with specific CIHC Interprofessional competency objectives, and scenario progressions. The scenario development continued over a three to five-week period. The faculty mentored the clinical champion project team on simulation and experiential activities, and debriefing on targeted CIHC competencies throughout the duration of the project and continued to provide ongoing coaching as needed to the teams, to ensure sustainability of results following the completion of the intervention.

\section{Research question}

Does a simulation based educational intervention coupled with non-medical experiential team base activities; improve individual knowledge, attitudes and team behaviours of health professionals?

\section{Methods}

Participants were conveniently sampled from both rural and urban healthcare centres in Western Canada including a trauma unit, paediatric rehabilitation unit and a medical centre. Participants represented 17 health professionals including physicians, residents, nurse practitioners, registered nurses, clinical nurse educators, registered respiratory therapists, emergency medical technicians, unit clerks, pharmacists, physiotherapists, occupational therapists, social workers, speech pathologist, and psychologists.

Individual changes in participants' knowledge, attitudes and team behaviours were assessed using a quasi-experimental, repeated measures study design. Participants' knowledge, attitudes and behaviours were assessed at the beginning of the first workshop (preintervention), and the end of the second workshop (post intervention).

\section{Measurement}

Outcome measures for the cognitive assessment included a 20-item multiple-choice questionnaire (MCQ) based on the IPC content from the asynchronous eLearning modules. The instrument was validated for content and face validity by a core team of interprofessional experts and project faculty. The knowledge test was administered at start of Workshop Day 1 and re-administered at end of Workshop Day 2 (pre-post intervention). The attitudinal assessment included the use of a validated scale [38] TeamSTEPPS Teamwork Attitudes Questionnaire (T-TAQ), which was also, was administered at start of Workshop Day 1 and re-administered at the end of Workshop Day 2 (pre-post intervention) [39]. The behavioural assessment of teamwork included a validated scale [40], Mayo High Performance Teamwork Scale (MHPTS). The MHPTS includes 8 -items which provided a representative sample of the range of key observable behaviors of high performance teams. The MHPTS consists of a behavioral anchored scale of 0 (never or rarely), 1 (inconsistently), 2 (consistently). This instrument is a previously validated tool with a Cronbach's alpha (0.85) suggesting an excellent internal consistency of a measure (i.e. items represent the construct of teamwork) used to measure behavioral change in teamwork after the simulation intervention. For simulations 1 and 4 the participants self-assed their teamwork performance using the MHPTS immediately following each simulation, prior to the group debrief. In addition, the project team faculty objectively assessed teamwork performance using the MHPTS at the same time points. Following the completion of the intervention, trained blinded raters ( 2 nurses, 1 physician and 1 researcher) reviewed the video recordings for simulations 1 and simulations 4 to assess change in participants' team behavious using the MHPTS. In addition to the MHPTS, the blind raters used the validated McMaster-Ottawa Team Observed Structured Clinical Encounter (TOSCE) scale [40] and provided global ranking score of participant's performance (scores between 1-10) based on the CIHC competencies. One month following the intervention, a convenient, purposeful, sample of participants were asked to participate in a follow up focus group session. The semi-structured interview guide focused on the enablers and barriers to the transfer the knowledge and skills gained from the workshop in teaching and transferring IP collective competencies to practice.

\section{Results}

\section{Demographics}

The intervention was inclusive of participants $(n=66)$ from 17 different professional groups. This included 17\% MDs ( $n=11), 47 \%$ Nurses $(n=31), 36 \%$ Allied Health $(n=23)$. Of the total participants, $36.4 \%$ had been practicing between $0-5$ years and $63.6 \%$ of the participants work on med/surgical units. Furthermore, $31.8 \%$ of participants had never participated in simulation prior to the intervention.

\section{Cognitive change}

Changes in knowledge were assessed using a 20-question knowledge test that was constructed by the core project faculty team. IP knowledge scores were compared before, after intervention. A change in cognitive awareness about collaborative practice was demonstrated with scores being significantly higher after the intervention $F(2,24)=1.51, p<0.05$. The preworkshop mean 14.00 (4.79) and post-workshop mean 16.04 (2.19). 


\section{Attitudinal change}

Interprofessional attitudes were assessed using the TeamSTEPPS T-TAQ validated questionnaire. The T-TAQ instrument assessed attitudes toward the core components of IPC: team structure, leadership, situation monitoring, mutual support, and communication. T-TAQ scoring can take one of two forms: a total score was calculated for each teamwork construct or an average score may be derived. The Cronbach's alpha (internal consistency for each of the constructs) is as follows: Team Structure $(r=0.70)$; Leadership $(r=0.81)$; Situation Monitoring ( $r=0.83)$; Mutual Support $(r=0.70)$; Communication $(r=0.74)$.

Statistically significant improvements in pre and post workshop means were found following the intervention for the subscales of Team Structure (25.86-27.14, $p<0.05)$, Leadership (27.36-29.69, $p<0.05)$ and Communication $(24.57-26.73, p<0.05)$, as well as for the total score $(123.85-129.07, p<0.05)$. Therefore participants had a significant overall change in attitudes toward teamwork across constructs for team structure, leadership, and communication.

Table 1 captures the changes in attitudes towards teamwork competencies, pre- and post-workshop means, standard deviations and the alpha values for each teamwork construct in the T-TAQ.

\section{Team behavioural change}

Changes in team behavior were assessed using the Mayo High Performance Teamwork Scale (MHPTS) [39], and the McMasterOttawa Team Observed Structured Clinical Encounter (TOSCE) [40]. In our intervention, the MHPTS was completed by the participants, workshop faculty, and blinded raters who reviewed videos of scenarios 1 and 4 . The TOSCE was only used by the 4 blinded raters who reviewed video recordings of simulation 1 and simulation 4 to assess global-ranking scores of participants' performance based on CIHC competencies.

Figure 1 shows the statistically significant behavioral changes in mean score that were noted for all the groups using the MHPTS. Participant Scores were analyzed using paired sampled t-tests: 11.42 ( $\mathrm{SD}=2.75)-13.58(\mathrm{SD}=3.40)$; paired $\mathrm{t}=-4.40, p<0.05$; faculty scores: $10.32(\mathrm{SD}=1.66)-14.67(\mathrm{SD}=1.89)$; paired $\mathrm{t}=-1.30, p<0.05$. Furthermore, a two-way repeated measure ANOVA shows a significant group effect between the blind rater's total MHPTS mean score preintervention $(\mathrm{M}=8.46, \mathrm{SD}=3.38)$ and post-intervention mean score $(\mathrm{M}=9.62, \mathrm{SD}=3.97), \mathrm{F}=1.125(1,24), p<0.05$. In addition, a significant group effect was found between the blind rater's total global TOSCE mean score pre-intervention $(\mathrm{M}=4.31, \mathrm{SD}=1.49)$ and post-intervention mean score $(\mathrm{M}=5.15 \mathrm{SD}=1.63), \mathrm{F}=6.307(1,24), p<0.05$. Rater effect and Interaction effect not detected for both measures $(p>0.05)$.

\section{Inter-rater Reliability of the Behavioral Rating Scales}

Inter-rater reliability training ( 4 hours) was given to the blind raters of 2 nurses, 1 physician and 1 researcher. Since behavioral anchored scales involved use of human judgment, they are vulnerable to rater effects (e.g., halo, rater leniency/hawk vs. dove rating). By providing rigorous training to the raters and development of clear item descriptors for the 8 items, we were able to calibrate the instrument to ensure consistency of the measures.

Consequently because of this rigorous inter-rater reliability training, there was strong significant correlation (convergent validity) between the total MHPTS score and global TOSCE score for the blind rater's $r=0.832, p<0.001$ (pre-intervention), and $r=0.766, p<0.001$ (post-intervention). The internal consistency (Cronbach's alpha) between the four blind raters for the TOSCE was $r=0.94$ for Workshop 1 and $r=0.74$ for Workshop 2. The weighted Kappa scores ( 3 ordinal data points) between the 4-blind raters for the 8-items of the MHPTS is as follows Item $1(r=0.71)$, Item $2(r=0.84)$, Item $3(r=0.92)$, Item $4(r=0.77)$, Item $5(r=0.86)$, Item $6(r=0.79)$, Item $7(r=0.95)$, Item 8 $(r=0.83)$. Thus, there was a very strong interrater reliability between the raters in discriminating between the items on the scale.

\section{Focus Groups: Transfer of collaborative practice knowledge, attitudes and behaviours}

A convenient, purposeful sample of health professional who participated in the intervention were asked to participate in a 1-month follow up focus group session. Three focus group sessions (60 minutes) were held with 5-6 participants 1-month following the last workshop at each of the 3 sites. The semi-structured interview guide focused on the enablers and barriers to transfer IP collaborative practice knowledge and skills gained from the workshop. Following transcription verbatim of the 3 focus group sessions, the agreement in coding of themes between the two coders was high (Kappa $=0.82)$. Thematic analysis of transcripts revealed key themes specific to: a) transfer of IP competencies to clinical practice, b) collaborative care, c) closed loop communication and d) speaking up. The narratives revealed key insights on the transfer of knowledge, skills of the workshops to clinical practice. For example, the participants reported an increased ability to question, clarify, and repeat back orders. Furthermore, the participants expressed that they felt more comfortable in clarifying who is the lead (including not always assuming the leader has to be a physician). There was also more awareness of the importance of reflective practice and consistent debriefing after clinical cases. Moreover, there was a greater sense of awareness of team process, what wrong/unsafe behaviour look like and confidence in participants' ability to apply the competencies within their own teams. In addition, participants noted the use of different language/phrasing to discussing IP conflict and interpersonal interactions and felt overall, improved interactions with physicians. Table 2 highlights qualitative narratives from the participants that directly related to the transfer of $\mathrm{CIHC}$ competencies to clinical practice.

\section{Discussion}

This innovative flip classroom curricular approach using SBE and team based experiential activities, validated through research evidence,

Table 1. Changes in Attitudes towards Teamwork Competencies

\begin{tabular}{|c|c|c|c|c|}
\hline $\begin{array}{c}\text { Construct } \\
* 5 \text { items for each subscale }\end{array}$ & $\mathbf{n}$ & $\begin{array}{c}\text { Mean pre-workshop } \\
\text { (Mean/SD) }\end{array}$ & $\begin{array}{c}\text { Mean post workshop } \\
\text { (Mean/SD) }\end{array}$ & $\begin{array}{c}\boldsymbol{p} \text { value (alpha) } \\
27.14(5.19)\end{array}$ \\
\hline Team Structure & 66 & $25.86(5.52)$ & $29.69(9.58)$ \\
\hline Leadership & 66 & $27.36(2.41)$ & $27.50(7.17)$ \\
\hline Situation Monitoring & 66 & $28.08(8.72)$ & $17.98(2.38)$ \\
\hline Mutual Support & 66 & $18.90(5.52)$ & $26.73(10.52)$ \\
\hline Communication & 66 & $24.57(7.13)$ & $p>0.05$ \\
\hline $\begin{array}{c}\text { Average } \\
\text { Total Score }\end{array}$ & 66 & $123.85(15.77)$ & $p<0.05$ & $129.07(16.29)$ \\
\hline
\end{tabular}


Table 2. Transfer of CIHC Competencies to Clinical Practice

\begin{tabular}{|c|c|}
\hline CIHC Competencies & Qualitative Narratives: Participant Quotes \\
\hline Interprofessional Conflict Resolution & $\begin{array}{l}\text { "The workshops taught us about what to look for...like establishing a leader, which were things we normally didn't really think } \\
\text { about." }\end{array}$ \\
\hline Collaborative Leadership & $\begin{array}{l}\text { "I noticed a difference in how one of the physicians that ran the team rounds ... One of the things that really came out during the } \\
\text { workshops was that many people want to say something and now feel empowered to do so." } \\
\text { "It was nice to explore with the team, instead of assuming that everyone has the same definition or understanding of those } \\
\text { competencies." }\end{array}$ \\
\hline Interprofessional Communication & $\begin{array}{l}\text { "It has increased my ability to question, clarify and report back on medication orders" } \\
\text { "I am more assertive in communicating their perspective and less likely to withhold information" } \\
\text { "Simulations showed us how, "we don’t really communicate [in our interprofessional practice] ...we're just asking for things." }\end{array}$ \\
\hline Team Functioning & $\begin{array}{l}\text { "If patients see you working together as a team it increases their trust in you." } \\
\text { "As a new person [to the team] I felt that this experience has been very valuable...it's like rocket-fuel. The eleven hours I spent at } \\
\text { the workshops has given me so much preparatory education. I got to know so many team members in ways that would've taken me } \\
\text { years to learn, and I learnt that in eleven hours with them. Felt that the SIMs gave participants an opportunity to learn how their team } \\
\text { members cope in certain situations and how they deal with patients/clients." }\end{array}$ \\
\hline Patient/Client/Family/Community-Centered Care & "I now have increased confidence to speak up and advocate for patients in difficult situations." \\
\hline Role Clarification & $\begin{array}{l}\text { "You don't want everyone just sticking to their roles because there should be overlap between the different positions. Sims } \\
\text { illustrated overlap between roles and reinforced the collaborative nature of the team." }\end{array}$ \\
\hline
\end{tabular}

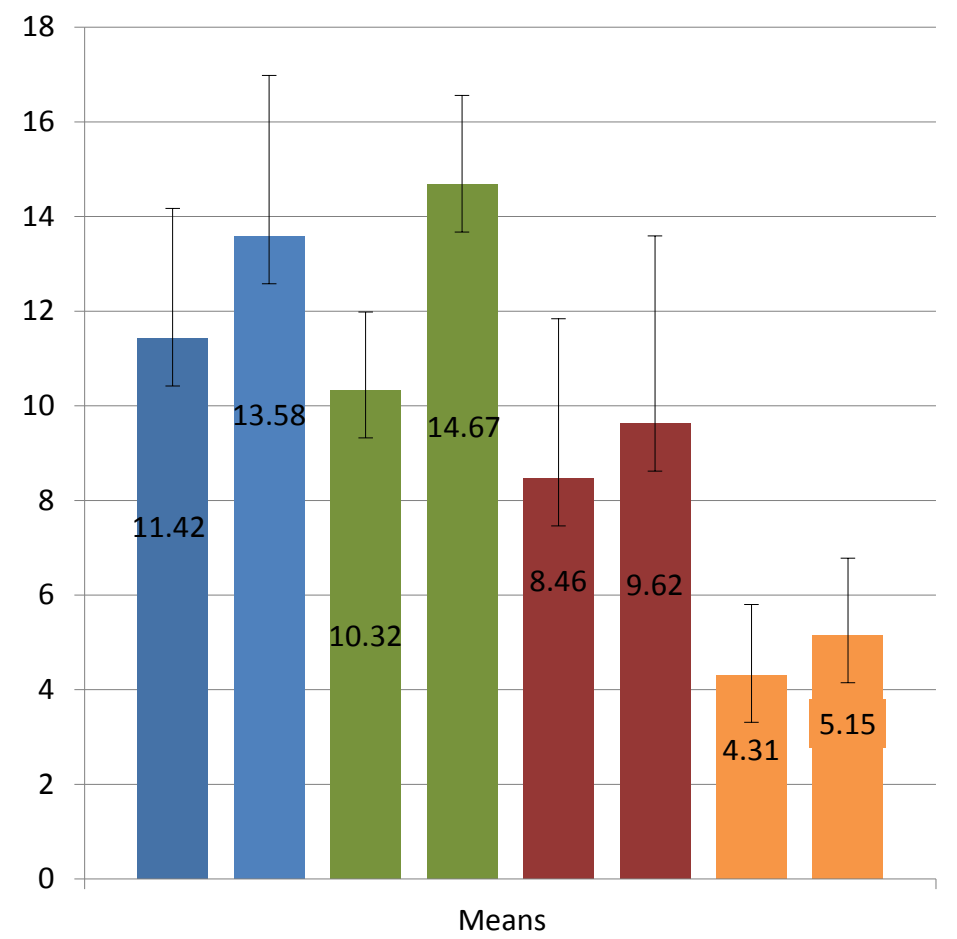

\author{
- Pre-Intervention \\ Participants \\ - Post-Intervention \\ Participants \\ - Pre-Intervention \\ Faculty \\ Post-Intervention \\ Faculty \\ MHPTS Score Pre- \\ Intervention Blind \\ Raters \\ - MHPTS Score Post- \\ Intervention Blind \\ Raters
}

Figure 1. Change in Team Behaviours: MHPTS and TOSCE is highly transferable across a variety of clinical settings, populations and levels of care and has shown to statistically significantly change frontline healthcare teams individual knowledge, attitudes and IPC team behaviours.

Traditionally in simulation team training, debriefing has been taught using a Crew (Crisis) Resource Management (CRM) framework. CRM was developed in the 1970's by the aviation industry following the realization that $70 \%$ of sentinel events were due to errors in communication [26]. Since that time, many high-risk work domains including healthcare have utilized CRM framework to debrief high functioning healthcare teams [41-43]. While CRM is effective framework to address individual team behaviours in simulation, it fails target IPC competencies and collective team behaviours, which was the focus of our intervention.

Thus building on the work of Lingard [44] in order to move towards IPC and collaborative care delivery, it has been recognized that health teams must be collectively competent. While individual competence is necessary in today's healthcare world, team members must move from thinking and acting as individually practitioners to thinking and acting as a competent collective team [44]. Thus to ground our study to build collective competence, we used the CIHC Interprofessional Framework and co-created the scenarios with an interprofessional clinical champion project team and simulation consultants. By having a collaborative approach to co-design and cocreate the objectives and scenario, we could build highly contextual and relevant interprofessional scenarios for each team. This also allowed the team members the ability to learn about, from and with each other during the process, and how their roles could overlap within a clinical scenario. Both the scenarios and experiential activities were debriefed in a way that deliberately used a hybrid approach to debriefing based on the traditional CRM team behaviors, in addition to the CIHC competencies. The objectives were clearly defined for each scenario 
Table 3. CRM and CIHC Implications and Considerations for Debriefing

\begin{tabular}{|c|c|c|c|}
\hline CRM Behaviour & CIHC Competency & Benefits for adding CIHC to Debriefing & Sample Debriefing Questions \\
\hline $\begin{array}{l}\text { Leadership } \\
\text { - Clear leader established } \\
\text { - Focused on team structure and ensuring a } \\
\text { clear leader is identified } \\
\text { - Summarizes and plans } \\
\text { - Controls workflow by delegating and } \\
\text { - } \text { prioritized feedback } \\
\text { feedback }\end{array}$ & $\begin{array}{l}\text { Collaborative Leadership } \\
\text { - Focus on working together including } \\
\text { patients and families. } \\
\text { - Defining a clear leader that is collaborative } \\
\text { with all team members. } \\
\text { - Recognizing that during a patient's clinical } \\
\text { course their team, including the leadership } \\
\text { may change multiple times. Collaboration } \\
\text { amongst those taking on the leadership role } \\
\text { is crucial. }\end{array}$ & $\begin{array}{l}\text { - Creating psychological safety around } \\
\text { leadership. } \\
\text { - Defining how to create a safe environment } \\
\text { for people to express their views and ideas, } \\
\text { no matter what the outcome. } \\
\text { - Frequently asking for, and considering } \\
\text { input from all team members. } \\
\text { - How are new team members incorporated } \\
\text { into the current team? How are departures } \\
\text { of team members handled? }\end{array}$ & $\begin{array}{l}\text { - How do you create psychology safety in } \\
\text { your team? What does this look like for } \\
\text { your team and your leaders? } \\
\text { - Specifically, how do you react and } \\
\text { respond when a team member brings up a } \\
\text { suggestion that is either correct and impacts } \\
\text { patient care/patient safety, or alternatively } \\
\text { is completely incorrect? } \\
\text { - How did the team decide who would take } \\
\text { on the leadership role? } \\
\text { - When team members noted changes to the } \\
\text { patient status or the environment how did } \\
\text { they decide whether or not to share the } \\
\text { information with the team and/or the team } \\
\text { leader? }\end{array}$ \\
\hline $\begin{array}{l}\text { CRM does not specifically reference IP } \\
\text { conflict resolution }\end{array}$ & $\begin{array}{l}\text { Interprofessional Conflict Resolution } \\
\text { - Actively engage self and others in } \\
\text { resolving interprofessional conflicts } \\
\text { (including patient and families). } \\
\text { - Recognizing potentially positive aspects } \\
\text { of conflict. }\end{array}$ & $\begin{array}{l}\text { - Effectively dealing with conflict is key to } \\
\text { high performing IP teams and collective } \\
\text { competence. } \\
\text { - Conflict is not always a negative, it can } \\
\text { be beneficial for mitigating the risks of } \\
\text { "groupthink" and other types of "fixation } \\
\text { errors". } \\
\text { - Not resolving conflict, is a barrier to } \\
\text { information sharing. For example, team } \\
\text { members withholding information to avoid } \\
\text { contact or conflict resolution with another } \\
\text { team member and collectively impacting } \\
\text { the plan of care. } \\
\text { - Conflict can be overt or covert, whatever } \\
\text { the form it needs to be recognized and } \\
\text { acknowledged in order to be dealt with. }\end{array}$ & $\begin{array}{l}\text { - How does conflict impact how you share } \\
\text { information with others? } \\
\text { - How does conflict impact your functioning, } \\
\text { team functioning and patient and family? } \\
\text { - When we don't resolve conflicts between } \\
\text { team members and other professions, how } \\
\text { is this perceived by patients and families? } \\
\text { - How is the presence of conflict identified? } \\
\text { Once conflict has been identified how is it } \\
\text { addressed by team members? } \\
\text { - What are the preferred conflict resolution } \\
\text { styles of the current team members? How } \\
\text { do these styles impact what happens when } \\
\text { conflict develops within the team? }\end{array}$ \\
\hline $\begin{array}{l}\text { Role Clarity } \\
\text { - Individual team members adopt a specific } \\
\text { role } \\
\text { - Provide information and feedback to the } \\
\text { team leader } \\
\text { - Prioritizes tasks, remains aware of the big } \\
\text { picture } \\
\text { - Understands their limits }\end{array}$ & $\begin{array}{l}\text { Role Clarification } \\
\text { - Understanding your own role but also the } \\
\text { role of other professions on the team. } \\
\text { - There is still a focus on training within like } \\
\text { professions versus learning about the roles } \\
\text { and abilities of other professions. }\end{array}$ & $\begin{array}{l}\text { - Team structure and being "individually } \\
\text { competent" on a team, versus } \\
\text { understanding all roles on the team and } \\
\text { how you work together to achieve a } \\
\text { common goal. } \\
\text { - Lack of understanding other roles and what } \\
\text { they can do to support the team functioning } \\
\text { in a given situation limits team's abilities } \\
\text { to become "collectively competent". }\end{array}$ & $\begin{array}{l}\text { - How do you gain a better understanding of } \\
\text { the other professional's roles on the team? } \\
\text { - What are the possible implications of not } \\
\text { knowing what other roles are on the team? } \\
\text { - What overlapping roles and responsibilities } \\
\text { can be utilized to effectively use resources? } \\
\text { How does the team align their roles to } \\
\text { make and share the best patient plan of care } \\
\text { to ensure roles and ensure tasks are not } \\
\text { being duplicated? } \\
\text { How does this shared plan impact patient } \\
\text { and family trust or how they view the } \\
\text { healthcare system? }\end{array}$ \\
\hline $\begin{array}{l}\text { Effective Communication } \\
\text { - Calling out critical information during } \\
\text { emergent events } \\
\text { - "Closed loop" communication structure } \\
\text { - Information sharing: Assertions and } \\
\text { Inquiry } \\
\text { - Respectful }\end{array}$ & $\begin{array}{l}\text { Interprofessional Communication } \\
\text { - References varying professions } \\
\text { communicating with each other in a } \\
\text { collaborative, responsive and responsible } \\
\text { manner. } \\
\text { - Explicitly includes communication with } \\
\text { patients and families. }\end{array}$ & $\begin{array}{l}\text { - Communication structure of individually } \\
\text { competent providers, versus how } \\
\text { competent providers communicate with } \\
\text { each other and the IP team to ensure the } \\
\text { message is heard and communication is } \\
\text { "closed loop". }\end{array}$ & $\begin{array}{l}\text { - What happens when multiple professions } \\
\text { enter a patient room at different times and } \\
\text { give their individual "profession focused" } \\
\text { care plans? Are these always aligned? } \\
\text { What does this duplication of information } \\
\text { sharing and "care plan making" do to a } \\
\text { patient/family view of the health care } \\
\text { system? }\end{array}$ \\
\hline $\begin{array}{l}\text { Anticipation and Planning } \\
\text { - Identify who needs to be there and the } \\
\text { required expertise } \\
\text { - Anticipate needs for drugs or equipment } \\
\text { - Attempt to take steps to prevent a crisis } \\
\text { - Proactive vs. reactive }\end{array}$ & $\begin{array}{l}\text { Team Functioning } \\
\text { - Not an explicit CIHC competency. } \\
\text { - Anticipation and planning are key } \\
\text { components to patient safety and team } \\
\text { functioning in critical events. } \\
\text { - Some simulation-based education programs } \\
\text { are engaging in "Just in Time" scenarios to } \\
\text { be able to anticipate and plan for potential } \\
\text { patient events. }\end{array}$ & $\begin{array}{l}\text { Teams must be able to anticipate and plan } \\
\text { together to be effective in being prepared } \\
\text { for potential next events. }\end{array}$ & $\begin{array}{l}\text { - How does the team support one another in } \\
\text { anticipation and planning? } \\
\text { - What does each profession think they need } \\
\text { to anticipate with this patient and what } \\
\text { does that look like? Are your roles and } \\
\text { responsibilities overlapping? } \\
\text { - How do you ensure everyone shares the } \\
\text { shared "mental model" and what could be } \\
\text { done to improve this? }\end{array}$ \\
\hline $\begin{array}{l}\text { Situational Awareness/Global Assessment } \\
\text { - Create a shared "mental model" } \\
\text { - Ensuring someone on the team has } \\
\text { "situational awareness" or awareness of } \\
\text { time, urgency, number of attempts at a } \\
\text { - skill, etc. } \\
\text { - Continually reassess the patient and } \\
\text { - } \text { - Monironment } \\
\text { - Avoid "fixation errors". }\end{array}$ & $\begin{array}{l}\text { Team Functioning } \\
\text { - Not an explicit CIHC competency. } \\
\text { - Many simulations focus on training teams } \\
\text { to maintain "situational awareness" when, } \\
\text { for example, a leader is forced to focus on } \\
\text { a task (such as intubation). }\end{array}$ & $\begin{array}{l}\text { - All team members must be trained in } \\
\text { the importance of gaining, and ensuring } \\
\text { someone has situational awareness and this } \\
\text { is not just the role of the leader. } \\
\text { - "Situational awareness" is especially } \\
\text { important when the leader is forced to } \\
\text { focus on a task. }\end{array}$ & $\begin{array}{l}\text { - How does the team ensure someone } \\
\text { is always in the role of maintaining } \\
\text { "situational awareness"? If it isn't the } \\
\text { leader at a point in time, who is it? } \\
\text { - Ensuring a "hands off' leader is ideal } \\
\text { for maintaining situational awareness } \\
\text { whenever possible. What strategies does } \\
\text { the team utilize to ensure someone on the } \\
\text { team has situational awareness when a } \\
\text { leader is called to perform a task? Who } \\
\text { is the best person for this at different } \\
\text { moments of this case? }\end{array}$ \\
\hline
\end{tabular}




\begin{tabular}{|c|c|c|c|}
\hline $\begin{array}{l}\text { Resource Utilization (Human resources, } \\
\text { equipment, supplies and space) } \\
\text { - Assigning tasks according to people's skill } \\
\text { level } \\
\text { - Balance workload } \\
\text { - Monitor proper operation of equipment }\end{array}$ & $\begin{array}{l}\text { Team Functioning } \\
\text { - Not an explicit CIHC competency. } \\
\text { - Training teams and individuals to preform } \\
\text { to full scope of practice. May require } \\
\text { 'letting go' of traditional roles that are } \\
\text { profession based and move to function to } \\
\text { their full abilities including overlapping } \\
\text { skill sets to support team functioning. }\end{array}$ & $\begin{array}{l}\text { - Understanding the concept that many } \\
\text { professions have overlapping skill sets. } \\
\text { Task interdependency and performing } \\
\text { tasks based on best available person in a } \\
\text { situation is more important than waiting for } \\
\text { a specific profession to perform a task if } \\
\text { others are able and qualified. }\end{array}$ & $\begin{array}{l}\text { - What are some of the overlapping roles } \\
\text { and responsibilities on this team? What } \\
\text { are the tasks that we had to perform in this } \\
\text { situation? Who is trained to do each one of } \\
\text { these, or alternatively it falls within your } \\
\text { scope of practice and you could be trained } \\
\text { to do these? } \\
\text { - What are the barriers of task } \\
\text { interdependency and cross training for } \\
\text { team functioning and patient care? }\end{array}$ \\
\hline $\begin{array}{l}\text { Patient/Client/Family/ Community } \\
\text { Centered Care } \\
\text { - Not an explicit CRM element. May be a } \\
\text { barrier to effectively functioning teams that } \\
\text { do not integrate the patient and family as a } \\
\text { member of the team. }\end{array}$ & $\begin{array}{l}\text { Patient/Client/Family/ Community } \\
\text { Centered Care } \\
\text { - Seek out, integrate and value input as a } \\
\text { partner, in designing and implementing } \\
\text { care services. }\end{array}$ & $\begin{array}{l}\text { - Collective competence and IPC focuses } \\
\text { on teams that are viewing the patient and } \\
\text { family as an integral member. Not an "us" } \\
\text { versus "them" approach. } \\
\text { - Transparently including family and patient } \\
\text { in care decisions, rounds and presence at } \\
\text { the bedside when reasonable emotional } \\
\text { states allows. }\end{array}$ & $\begin{array}{l}\text { - How do you view the relationship between } \\
\text { the patient/family and the healthcare team? } \\
\text { - How does the current situation look from } \\
\text { the patient's or family's perspective? } \\
\text { - What were the priorities of the patient/ } \\
\text { family at that point in their care? }\end{array}$ \\
\hline $\begin{array}{l}\text { Team Functioning } \\
\text { - Not an explicit CRM element. } \\
\text { - Focus on team structure is important } \\
\text { for developing highly reliable team } \\
\text { behaviours. }\end{array}$ & $\begin{array}{l}\text { Team Functioning } \\
\text { - Practitioners understand the principles of } \\
\text { team dynamics and group processes to } \\
\text { enable effective IPC. }\end{array}$ & & $\begin{array}{l}\text { - What kind of team dynamics and processes } \\
\text { positively impact team functioning? } \\
\text { - What kind of team dynamics and processes } \\
\text { negatively impact team functioning? } \\
\text { - What stage of team development are you } \\
\text { currently at? What are the implications of } \\
\text { this stage? }\end{array}$ \\
\hline
\end{tabular}

to focus on 2 of the IP competencies; the greatest focus was on the 2 CIHC competencies that were revealed in the needs assessment survey as posing the greatest challenge to each specific team. It is hypothesized that is was this novel approach to debriefing that positively contributed to the statistically significant changes in knowledge, attitudes, and team behaviors that we observed in our intervention.

Table 3 below outlines some key considerations and potential gaps when debriefing interprofessional teams using only CRM elements and/or the CIHC competencies. The authors' purpose is to highlight the need for a hybrid approach of both frameworks when building IPC competencies and highly reliable healthcare teams. The first two columns provide the specific CRM behaviours and CIHC competencies. The third column highlights benefits to adding CIHC to your debriefing toolkit and its influences on building collective competence. The final column provides consideration for debriefing queries, and sample questions to facilitate discussion around IPC and collective competence.

A surprising finding that was realized during the curriculum delivery was the unintentional relevance of using experiential activities with this hybrid debriefing approach of CRM and CIHC frameworks. As our teams moved from clinically relevant simulation scenarios and debriefing in their traditional medical role, to participating in experiential activities that were of a team based context and had no relevance to what role they held on the medical team, there was a rapid uptake and application of team behaviours and IPC skills. The teams would move from the simulations to experiential activities and back again, each followed with debriefing. This approach was highly effective in reducing silos between professional groups, significantly reducing hierarchical impacts between team roles, and built a new model by which teams would openly and safely discuss teamwork principles in a psychologically safe way. For example, when a trauma team physician who was traditionally in a leadership role on the medical team; was now in a supportive followership role while the $\mathrm{RN}$ or allied health team member was assigned the leadership role in an experiential activity. When they then returned back to a medical simulation in their traditional roles, there were significant improvements to teamwork behaviours and IPC. Several qualitative narratives (Table 2) expressed by the team indicated a greater ability to talk to each other, a higher confidence and greater ability to pursue communications between team members, and the critical importance of having the ability to reflect through debriefing and talk together about challenges within their teams and how to collectively solve them as a team.

Manyelements of thisprojectare consistent with other contemporary initiatives to specifically improve teamwork behaviours within a medical context [45]. It is possible that our flipped classroom approach, along with the specific emphasis place on teamwork behaviours, both during the simulations and the non-medical experiential team based learning activities resulted in a successful scaffolding of learning [46,47]. This further allowed for the breakdown of traditional constraints that are associated with the attribution of certain behaviours to traditional roles on the medical team. Subsequently this behaviour was transferred to the debriefing conversations following both the simulations and experiential activities. This is important given the complexity of the current healthcare system, where the oversimplification caused by the misattribution of observed behaviours to professional stereotypes rather than the nuances of situational priorities and perspectives [44]. The proposed mechanism for this successful scaffolding [46,47] can be attributed to the initial experience of team performance in a clinical context. By necessity during the subsequent debriefing, observed team behaviours are often associated with and attributed to professional roles and scopes of practice. While debriefing of such behaviours is beneficial, it is also often insufficient for the specific identification of teamwork behaviours and their transferability to different contexts. However, in the subsequent experiential learning activities, removing the clinical context allows for the specific examination of teamwork behaviours, and the consequent theoretical mental re-integration into a clinical context. Finally, the subsequent simulation experiences allow for participants to once again apply the teamwork behaviours discussed within a clinical context. Noteworthy, in this innovative curricular design for IPC education the participants had six different opportunities to reflect on teamwork behaviours, four within a clinical context, and two based on non-clinical experiential learning activities. The scaffolding process also included the time between and following the workshops, when participants returned to their regular clinical practice contexts with an expectation that they would apply the teamwork and IPC behaviours that had been discussed. The successes and challenges they encountered were then included in the debriefing 
in the subsequent workshop sessions and the final follow-up to promote sustainment of results and ongoing integration of teamwork behaviours and IPC into practice.

\section{Conclusions}

The demand for IPC education continues to grow globally $[8,48]$. There is an increasing need to develop a body of evidence on how to design, deliver and debrief competency based experiential SBE curriculum for practicing healthcare professionals, and measure its impact on changing knowledge, attitudes and team behaviors $[14,49]$. When designing, delivering and debriefing an IPC competency based curriculum, educators may want to consider a number of salient features that were unique to our evidence based intervention. Firstly, given the reported variances between different contexts and clinical settings, we demonstrated the critical importance of co-creation and co-design of the objectives, scenario and debriefing plan alongside frontline teams based on their unique medical contexts and IPC challenges. Secondly, there are very few reported opportunities for healthcare professionals to practice and gain proficiency in knowledge, skills and attitudes related to IP competencies. To demonstrate behavioral change, frontline practitioners require a combined approach of both experiential team based activities and simulation based learning. Finally, the importance of a needs assessment to diagnose the greatest IPC challenge for each specific team, in addition to having trained educators who can debrief both the scenarios and experiential activities using the novel hybrid approach based on CRM and CIHC framework are all critical features to deliver and design an evidence based IPC competency based curriculum. In summary, our evidence-based intervention demonstrated good generalizability across three different rural and urban clinical sites provincially and reported consistency of findings regardless of not having a comparison/control group as part of the study. Further research is needed to replicate this evidence base approach in validating the internal validity of the IPC curriculum design in demonstrating positive changes in knowledge, attitude, and team behaviors.

\section{Competing interests}

No competing interests

\section{Acknowledgments}

Marilyn Willison-Leach, Jennifer Loken, Dr. Ian Wishart, Dr. Steve Lapushinsky, Dr. Esther Suter, Diane McGregor, Sabrina Gilani

\section{Funding/Support}

This work was supported by the Workforce Policy and Planning, Health Workforce Division, Alberta Health

\section{Ethical approval}

Full Ethical Approval (REB13-1164) from the REB (Research Ethics Board) at the University of Calgary.

\section{References}

1. Bressler T, Persico L (2016) Inteprofessional education: Partnerships in the educational process. Nurse Educ Pract 16: 144-147. [Crossref]

2. Salas E, Rosen M (2013) Building high reliability teams: Progress and some reflections on teamwork training. BMJ Qual Saf 22: 369-373. [Crossref]

3. Canadian Patient Safety Institute (CPSI). Canadian framework for teamwork and communication: literature review, needs assessment, evaluation of training tools and expert consultations.
4. Hinde T, Gale T, Anderson I, Roberts M, Sice P (2016) A study to assess the influence of interprofessional point of care simulation training on safety culture in the operating theatre environment of a university teaching hospital. Journal of Interprofessional Care 30: 251-253.

5. King J, Anderson CM (2012) The Canadian interprofessional patient safety competencies: Their role in health-care professionals' education. J Patient Saf 8: 3036. [Crossref]

6. Kohn L, Corrigan J, Donaldson M (1999) To Err is Human - Building a Safer Health System. Washington, DC: National Academy Press.

7. Centre for the Advancement of Interprofessional Education (CAIPE). Defining IPE.

8. Interprofessional Education Collaborative Expert Panel (IPEC). Core Competencies for Interprofessional Collaborative Practice: 2016 Update.

9. Canadian Interprofessional Health Collaborative (CIHC). A national Inteprofessional Competency framework. 2010.

10. Lingard L (2016) Paradoxical truths and persistent myths: Reframing the team competence conversation. J Contin Educ Health Prof 36: S19-21. [Crossref]

11. Goldman J, Kitto S, Reeves S (2017) Examining the implementation of collaborative competencies in a critical care setting: Key challenges for enacting competency-based education. J Interprof Care 21:1-9. [Crossref]

12. Paige J, Garbee D, Brown K, Rojas J (2015) Using simulation in interprofessional education. Surg Clin North Am 9: 751-766. [Crossref]

13. Thistlethwaite J, Forman D, Matthews L, Rogers G, Steketee C, et al. (2014) Competencies and frameworks in interprofessional education: A comparative analysis. Acad Med 89: 869-875. [Crossref]

14. Reeves S, Perrier L, Freeth D, Zwarenstein M (2013) Interprofessional education: effects on professional practice and healthcare outcomes (update). Cochrane Database Syst Rev 28: CD002213. [Crossref]

15. Palaganas J, Epps C, Raemer D (2014) A history of simulation-enhanced interprofessional education. J Interprof Care 28: 110-115. [Crossref]

16. Boet S, Bould M, Burn C, Reeves S (2014) Twelve tips for a successful interprofessional team-based high-fidelity simulation education session. Med Teach 36: 853-857. [Crossref]

17. Accreditation of Interprofessional Health Education (AIPHE). Principles and practices for integrating interprofessional education into the accreditation standards for six health professions in Canada. Health Canada.

18. Dorval E, Thornby KA, Ottman A, Hubbard M (2017) Useful resources for members serving on a curriculum committee in schools and colleges of pharmacy. Currents in Pharmacy Teaching and Learning 9: 145-154.

19. Grant R, Goldman J, LeGrow K, MacMillan K, van Soeren M (2016) A scoping review of interprofessional education within Canadian nursing literature. J Interprof Care 30: 620-626. [Crossref]

20. Leclair L, Dawson M, Howe A, Hale S, Zelman E, et al. (2017) A longitudinal interprofessional simulation curriculum for critical care teams: Exploring successes and challenges. J Interprof Care 32: 386-390. [Crossref]

21. Gilfoyle E, Koot DA, Annear JC, Bhanji F, Cheng A, et al. (2017) Improved clinica performance and teamwork of pediatric interprofessional resuscitation teams with a simulation-based educational intervention. Pediatr Crit Care Med 18: e62-e69. [Crossref]

22. Baker L, Egan-Lee E, Marimianakis M, Reeves A (2011) Relationships of power: Implications for interprofessional education. J Interprof Care 25: 98-104. [Crossref]

23. Visser C, Ket J, Croiset G, Kusurkar R (2017) Perceptions of residents, medical and nursing students about interprofessional education: A systematic review of the quantitative and qualitative literature. BMC Medical Education 17: 77.

24. Reeves S, Fletcher S, Barr H, Birch I, Boet S, et al. (2016) A BEME systematic review of the effects of interprofessional education: BEME Guide No 39. Med Teach 38 656-668. [Crossref]

25. Sargeant $\mathrm{J}(2009)$ Theories to aid understanding and implementation of interprofessional education. J Contin Educ Health Prof 29: 178-184. [Crossref]

26. Ostergaard D, Dieckmann P, Lippert A (2011) Simulation and CRM. Best Practice \& Research Clinical Anesthesiology 25: 239-249.

27. Rosen M, Salas E, Wu T, Silvestri S, Lazzara EH, et al. (2008) Promoting teamwork: An event-based approach to simulation-based teamwork training for emergency medicine residents. Acad Emerg Med 15: 1190-1198. [Crossref] 
28. Reeves S, van Schaik S (2012) Simulation: a panacea for interprofessional learning? $J$ Interprof Care 26: 167-169. [Crossref]

29. Cheng A, Morse K, Rudolph J, Arab AA, Runnacles J, et al. (2016) Learner-centered debriefing for health care simulation education. Simul Healthc 11: 32-40. [Crossref]

30. Eppich W, Howard V, Vozenilek J, Curran I (2011) Simulation-based team training in healthcare. Simul Healthc 6: S14-S19. [Crossref]

31. Boet S, Pigford AA, Fitzsimmons A, Reeves S, Triby E, et al. (2016) Interprofessional team debriefings with or without an instructor after a simulated crisis scenario: An exploratory case study. J Interprof Care 30: 717-725. [Crossref]

32. Wong A, Gang M, Szyld D, Mahoney H (2016) Making an attitude adjustment": Using simulation-enhanced interprofessional education strategy to improve attitudes toward teamwork and communication. Simul Healthc11: 117-125. [Crossref]

33. Foronda C, MacWilliams B, McArthur E (2016) Interprofessional communication in healthcare: An integrative review. Nurse Educ Pract 19: 36-40. [Crossref]

34. Kern DE, Thomas PA, Hughes MT (2009) Curriculum development for medical education: a six- step approach. Maryland: The Johns Hopkins University Press.

35. Prober CG (2012) Lecture halls without lectures--a proposal for medical education. The New England Journal of Medicine 366: 1657.

36. McLaughlin JE, Roth MT, Glatt DM, Gharkholonarehe N, Davidson CA, et al. (2014) The flipped classroom: A course redesign to foster learning and engagement in a health professions school. Acad Med 89: 236-243. [Crossref]

37. Eppich W, Cheng A (2015) Promoting Excellence and Reflective Learning in Simulation (PEARLS): Development and rationale for a blended approach to health care simulation debriefing. Simul Healthc 10: 106-115. [Crossref]

38. Baker D, Amodeo A, Krokos K, Slonim A, Herrera H (2010) Assessing teamwork attitudes in healthcare: Development of the TeamSTEPPS teamwork attitudes questionnaire. Qual Saf Health Care 19 e49: 1-4. [Crossref]
39. Malec J, Torsher L, Dunn W, Wiegmann DA, Arnold JJ, et al. (2007) The Mayo high performance teamwork scale: Reliability and validity for evaluating key crew resource management skills. Simul Healthc 2: 2-10. [Crossref]

40. Solomon P, Marshall D, Boyle A, Burns S, Casimiro LM, et al. (2011) Establishing face and content validity of the McMaster-Ottawa team observed structured clinical encounter (TOSCE). J Interprof Care 25: 302-304.

41. O’Dea A, O'Connor P, Keogh I (2014) A meta-analysis of the effectiveness of crew resource management training in acute care domains. Postgraduate Medical Journal 90: 699-708.

42. Fung L, Boet S, Bould M, Qosa H1, Perrier L, et al. (2015) Impact of crisis resource management simulation-based training for interprofessional and interdisciplinary teams: A systematic review J Interprof Care 29: 433-444. [Crossref]

43. Shapiro M, Morey J, Small S, V Langford, C Kaylor, et al. (2004) Simulation based teamwork training for emergency department staff: Does it improve clinical team performance when added to an existing didactic teamwork curriculum? Quality \& Safety in HealthCare 13: 417-421. [Crossref]

44. Lingard L, McDougall A, Levstik M, Chandok N, Spafford MM, et al. (2012) Representing complexity well: A story about teamwork, with implications for how we teach collaboration. Med Educ 46: 869-877. [Crossref]

45. Cumin D, Skilton C, Weller J (2017) Information transfer in multidisciplinary operating room teams: a simulation-based observational study. BMJ Quality \& Safety 26: 209-216.

46. Kneebone RL, Scott W, Darzi A, Horrocks M (2004) Simulation and clinical practice: Strengthening the relationship. Med Educ 38: 1095-1102. [Crossref]

47. Bradley P, Postlethwaite K (2003) Simulation in clinical learning. Med Educ 37: 1-5. [Crossref]

48. World Health Organization (WHO). Framework for action on interprofessional education \& collaborative practice. Geneva, Switzerland.

49. Abu-Rish E, Kim S, Choe L, Varpio L, Malik E, et al. (2012) Current trends in interprofessional education of health sciences students: A literature review. J Interprof Care 26: 444-451. [Crossref]

Copyright: (C2018 Kaba A. This is an open-access article distributed under the terms of the Creative Commons Attribution License, which permits unrestricted use, distribution, and reproduction in any medium, provided the original author and source are credited. 